\title{
Gender differences in externalizing and internalizing problems in Singaporean children and adolescents with attention-deficit/ hyperactivity disorder
}

Tsz Wing Ivy Lau', Choon Guan Lim¹, Sanchalika Acharryya², Nikki Lim-Ashworth', Yi Ren Tan and Shuen Sheng Daniel Fung ${ }^{1 *}$ (1)

\begin{abstract}
Background: Studies on gender differences in attention-deficit/hyperactivity disorder (ADHD) comorbidities in the Asian populations have been limited and previous studies have shown inconclusive findings. Singapore is a city-state country in Southeast Asia with a population of 5.7 million. This study examined gender differences in internalizing and externalizing problems in Singaporean children and adolescents with ADHD. The plausible social factors underlying the gender differences were discussed.

Methods: A total of 773 participants (aged 6 to 18, 88\% males) newly diagnosed with ADHD were recruited from the largest public child and adolescent psychiatric center in Singapore. Their internalizing and externalizing problems were assessed using the Child Behavioral Checklist and Teacher's Report Form by parents and teachers respectively. Demographics and relevant social factors were collected using parent questionnaires.

Results: Females with ADHD were reported to have less delinquent and aggressive behavior but more depressive symptoms than their male counterparts, similar to findings in the Western literature. Gender remained a significant predictor of externalizing problem after controlling for other factors. Lower socioeconomic status and parental use of physical punishment were significant predictors of both internalizing and externalizing problems.

Conclusions: Gender differences in ADHD comorbidities do exist in the Asian clinical population. The lack of externalizing symptoms in females with ADHD has made timely referral and diagnosis challenging. More research is needed in understanding the gender differences in ADHD and the biopsychosocial mechanism underlying the differences in order to improve the detection of ADHD in females.
\end{abstract}

Keywords: Attention-deficit/hyperactivity disorder, ADHD, Gender comparison, Internalizing, Externalizing, Asia, Children and adolescents

*Correspondence: daniel_fung@imh.com.sg

${ }^{1}$ The Institute of Mental Health, Buangkok Green Medical Park 10 Buangkok View, Singapore 539747, Singapore

Full list of author information is available at the end of the article

\section{Background}

Singapore is an island city-state country of about $710 \mathrm{~km}^{2}$ in Southeast Asia with a population of $5.7 \mathrm{mil}-$ lion [1]. Attention-deficit/hyperactivity disorder (ADHD) is a neurodevelopmental disorder that has been reported to affect $3-7 \%$ of school-age children worldwide $[2,3]$. In Singapore, a nationwide epidemiological study on

(c) The Author(s) 2021. This article is licensed under a Creative Commons Attribution 4.0 International License, which permits use, sharing, adaptation, distribution and reproduction in any medium or format, as long as you give appropriate credit to the original author(s) and the source, provide a link to the Creative Commons licence, and indicate if changes were made. The images or other third party material in this article are included in the article's Creative Commons licence, unless indicated otherwise in a credit line to the material. If material is not included in the article's Creative Commons licence and your intended use is not permitted by statutory regulation or exceeds the permitted use, you will need to obtain permission directly from the copyright holder. To view a copy of this licence, visit http://creativeco mmons.org/licenses/by/4.0/. The Creative Commons Public Domain Dedication waiver (http://creativecommons.org/publicdomain/ zero/1.0/) applies to the data made available in this article, unless otherwise stated in a credit line to the data. 
the prevalence of ADHD is not available at the time of this publication. According to a school-based study sampling 2139 children in Singapore, 4.9\% of children were reported to have clinically significant behavioral problems [4]. ADHD was noted to be the leading diagnosis at the clinics of the Department of Developmental Psychiatry (DDP) at the Institute of Mental Health (IMH) which has been the largest public service provider of such specialty care in the country [5]. Apart from IMH, child and adolescent psychiatric service is also available at other restructured public hospitals and private mental health services in Singapore. In addition to psychiatrists, there are also clinical psychologists, occupational therapists, medical social workers and school counsellors who play a significant role in child and adolescent mental health services.

It is well known that ADHD affects more males than females and the gender ratio differs between the clinical samples and community samples. In a meta-analysis of 97 studies with community samples, the male to female ratio was reported to be about 3:1 [6]. In the clinical samples, the male to female ratio varied from 5:1 to $16: 1$ [2, 7-11]. The discrepancy between the clinical and community samples has suggested under-identification of ADHD in girls, probably due to the gender differences in the ADHD symptoms and comorbidities $[9,12]$. Although researchers have recognized gender as a significant moderator of ADHD presentation for more than two decades, research on gender comparisons in ADHD has been limited due to the lower prevalence of ADHD in females.

Before the change from ADHD 'subtypes' to 'presentations' in the fifth edition of the Diagnostic and Statistical Manual of Mental Disorders [13], past studies have shown that females were more likely to be diagnosed with the 'predominantly inattentive subtype' while males were more likely to be of the 'predominantly hyperactive and impulsive subtype' $[9,12,14-16]$. However, there were studies that did not observe any gender differences in inattention, hyperactivity and impulsivity which suggested that females and males with ADHD were similar, especially in the clinical samples $[8,9,11]$. By comparing performance in cognitive tests measuring processing speed, inhibition and working memory between genders, Arnett et al. [14] postulated that gender differences in ADHD severity could be partially moderated by certain cognitive endophenotypes, suggesting a role of genetics in the gender differences. Although Arnett et al. [14] reported that males with ADHD were rated as more inattentive than their female counterparts by parents and teachers, a meta-analysis of studies using the Continuous Performance Test reported no gender differences in inattention but males with ADHD were more impulsive than females with ADHD [17].
Other than differences in core symptoms of ADHD, it has been reported that males and females with ADHD displayed different comorbidity profiles. In general, males with ADHD presented with externalizing problems such as conduct disorder and oppositional defiant disorder while females with ADHD presented with more internalizing problems such as anxiety and depression [9, 12, 18-20]. Similar gender discrepancy was reported in adults with ADHD in a recent Norwegian populationbased study [21]. In addition, female adolescents with ADHD have been shown to suffer more peer rejection, poorer perceived locus of control and were more likely to be admitted for psychiatric issues in adulthood than their male counterparts [22, 23].

In addition to gender, age is another factor that moderates ADHD symptoms and comorbidities. In a prospective study of 128 boys with ADHD, decline in ADHD symptoms, especially hyperactivity and impulsivity, was noted as they grew up [24]. However, inattention problem was shown to be more persistent [25]. Comorbidities of ADHD also vary with age. Early age of onset has been shown to be associated with more aggressive problems while a later age of onset was associated with more anxiety and depressive symptoms [26].

To date, most studies on gender differences on ADHD have been done in the western population. Not much is known about the gender differences in the developmental population in Asia. Due to cultural differences, the perception of hyperactivity, the stigma of ADHD and the threshold of seeking professional help may be different in the Asian population. The limited studies in Asia suggested no gender differences in terms of ADHD symptoms and comorbidities $[8,11]$. However, the numbers of females included in these studies were limited with 10 females in the Korean study [8] and 21 females in the Taiwanese study [11], which may have limited the statistical power of the comparison. Studies with a representative sample of females are needed to clarify gender differences in the Asian context.

This study aimed to examine the distribution of externalizing and internalizing symptoms between males and females with ADHD as well as between predefined age groups using parent-reports and teacher-reports through an Asian clinical sample, with adequate representation from each gender. The primary hypothesis was that females with ADHD would present with fewer externalizing and more internalizing symptoms compared to males with ADHD. We also hypothesized that the gender differences might be further moderated by age. The secondary aim attempted to investigate the effects of age, socioeconomic status, use of physical punishment and aggression between parents on internalizing and externalizing problems in ADHD. It was hypothesized that younger age, 
lower socioeconomic status, use of physical punishment and aggression between parents would be associated with more externalizing problems and older age would be associated with more internalizing problems.

\section{Methods}

\section{Participants and procedures}

This was a retrospective study utilizing an existing database (reference number IMH/2005-0005) maintained by DDP at IMH. Children and adolescents with learning, emotional or behavioral problems were referred to DDP clinics by parents, schools or medical doctors [27]. The registered database included information collected from 773 children and adolescents, aged 6 to 18, who had their first consultations at DDP clinics during 2005 to 2007. They were newly diagnosed with ADHD by the attending psychiatrists using the International Classification of Diseases, Ninth Revision, Clinical Modification (ICD-9-CM) based on clinical assessment which included a comprehensive interview with the young person and family, a structured report from the teacher and a computerized test of attention.

\section{Measures}

All data was collected as part of routine assessments at the first clinic consultation. Written consents to use the collected data for research purposes were obtained from parents at the first clinic visit. Parents completed the Child Behavior Checklist (CBCL 6-18) while a school teacher who was familiar with the participant completed the Teacher's Report Form (TRF).

\section{CBCL and TRF}

Both CBCL and TRF are commonly used behavioral measures describing a child's behavioral, emotional, and social problems over the past 6 months [28]. The version of CBCL and TRF for aged 6 to 18 was used in this study. Both CBCL and TRF have been demonstrated to have good internal consistency and criterion validity in Singapore. The Cronbach alphas for CBCL internalizing problems and externalizing problems were found to be 0.89 and 0.91 respectively while the alphas for TRF internalizing and externalizing problems were 0.88 and 0.95 respectively in Singapore [27]. There are 113 items in total e.g. "Cries a lot", "Lying or cheating". The items in CBCL and TRF are largely identical except for some items which have been adapted for the specific context. The scoring is the same for both measures. For each item, the score ranges from $0=$ not true, $1=$ somewhat/ sometimes true, to $2=$ very/often true. There are eight syndrome scales, namely anxious/depressed, withdrawn/ depressed, somatic complaints, social problems, thought problems, attention problems, rule-breaking behavior and aggressive behavior. The syndrome scale scores are the sum of certain relevant item scores and the scores for internalizing problems and externalizing problems are the sum of specific syndrome scale scores. In this study, the raw scores of the CBCL and TRF scales were compared between genders as the raw scores reflect a better spread of data and allow a more sensitive comparison for research purposes [28].

Apart from CBCL, parents completed a standardized questionnaire which was adapted from the Ontario Child Health Study [29]. The questionnaire covered demographics of the child and parents, child's medical and psychiatric histories, family psychiatric history, stressful life events, family functioning and parenting style. To investigate the effect of certain social factors on internalizing and externalizing problems, relevant items of the questionnaire were extracted for analysis.

Parental education levels and whether they have experienced financial problems were extracted as proxy of socioeconomic status of the family. Their educational levels were categorized into two levels: secondary education or below and post-secondary education.

To study the relationship between physical punishment and internalizing and externalizing problems, two relevant items were extracted. They were whether parents (1) spanked the young persons or (2) hit them with an object. To facilitate multivariate analysis, parents' responses were coded as $0=$ no physical punishment in disciplining, $1=$ spanked or hit with an object, and $2=$ spanked and hit with an object.

Psychological aggression between spouses was assessed by asking parents whether these statements were true or not: "When you had disagreements with your spouse, you resolved it by (1) raising voices and yelling at each other; (2) refusing to talk; (3) insulting or swearing; (4) crying and (5) leaving the room to avoid continuing the argument". These statements were extracted from the Conflict Tactics Scale which was designed to explore conflict and violence within a family [30]. The responses to these items were all 'yes $=1$ point' or 'no $=0$ point'. The total score for psychological aggression was measured as the sum of the five items.

\section{Data analysis}

Distribution of demographic and clinical characteristics of the study population by gender was summarized using appropriate statistical measures. Internalizing and externalizing problem scores and syndrome scale scores of CBCL and TRF were compared between males and females. To study the effect of age on the above scores, the subjects were dichotomized into two age groups, 6 to 12 years old and 13 to 18 years old for comparison. The cut-off at 12 years old was chosen because it is the typical 
age when Singaporean students are being promoted from primary education to secondary education with significant changes in school environment. Normality checking was done by visual inspection of data distribution and Kolmongorov-Smirmov and Shapiro-Wilk tests. Mann-Whitney test was used for between genders and between age groups comparison in view of non-normal distribution of data and uneven group sizes with unequal variance. Effect sizes were calculated using the formula $r=Z / \sqrt{ } N$, where $N=$ number of observations [31]. Multiple linear regression models were developed separately for internalizing and externalizing scores using gender, age, gender $\times$ age interaction and other variables as explanatory variables to identify their association with internalizing and externalizing problems. Assumptions of linear relationship, multivariate normality, non-multicollinearity and homoscedasticity were met. Analysis was performed at two sided 5\% significance level using SPSS version 24. Missing values for any of the variables were excluded.

\section{Results}

Among the 773 children and adolescents, there were 677 males and 96 females with a male to female ratio of 7:1. The gender ratio was consistent with those found in overseas and local clinical studies [11, 12, 32]. Out of the 773 participants, 561 (72\%) participants, including 72 females and 489 males, have completed CBCL (Fig. 1). Among those with completed CBCL, $41.0 \%$ of mothers completed post-secondary education, compared to $32.3 \%$ of mothers in the group of incomplete CBCL, $\chi^{2}(1)=4.95$, $p<0.05$. There were no statistically significant differences in fathers' education level, ethnicity, type of housing, or parental occupation categories between the two groups.

The demographics and other characteristics of the participants were presented in Table 1. Eighty percent of

773 participants ( 96 females, 677 males), aged 6 to 18, newly diagnosed with ADHD.

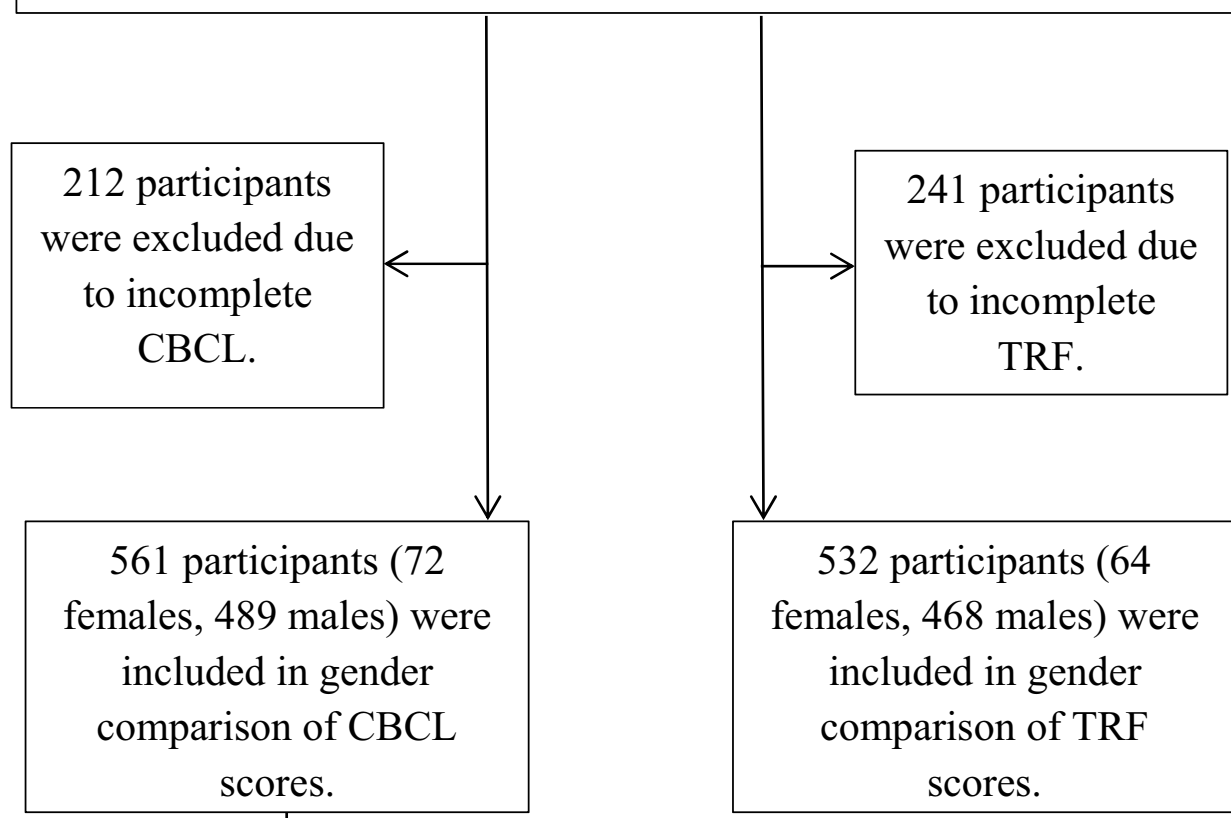

$$
\begin{gathered}
\text { Multivariate analysis } \\
\text { exploring effects of } \\
\text { different factors on CBCL } \\
\text { internalizing and } \\
\text { externalizing scores. }
\end{gathered}
$$

Fig. 1 Flow diagram in analysis of CBCL and TRF scores 
Table 1 Demographic and other variables by gender

\begin{tabular}{|c|c|c|}
\hline & Female & Male \\
\hline Number & 96 & 677 \\
\hline Age range & $6-15$ & $6-18$ \\
\hline Mean age $(S D)$ & $8.80(1.88)$ & $8.76(2.18)$ \\
\hline \multicolumn{3}{|l|}{ Ethnicity (\%within gender) } \\
\hline Chinese & 81.8 & 80.0 \\
\hline Indian & 9.1 & 7.0 \\
\hline Malay & 4.5 & 4.2 \\
\hline Others & 4.5 & 8.7 \\
\hline \multicolumn{3}{|l|}{ Mother's education level (\%within gender) } \\
\hline Secondary education or below & 52.7 & 61.4 \\
\hline Post-secondary or above & 47.3 & 37.4 \\
\hline Others & 0.0 & 1.2 \\
\hline \multicolumn{3}{|l|}{ Father's education level (\%within gender) } \\
\hline Secondary education or below & 48.3 & 54.6 \\
\hline Post-secondary or above & 49.4 & 43.4 \\
\hline Others & 2.3 & 2.1 \\
\hline Experienced financial problems & 12.0 & 9.7 \\
\hline \multicolumn{3}{|l|}{ Psychological aggression between spouses (\%within gender) } \\
\hline Yell at spouse & 36.9 & 41.3 \\
\hline Refuse to talk & 40.5 & 35.4 \\
\hline Cry & 15.5 & 9.5 \\
\hline Insult or swear & 3.6 & 3.6 \\
\hline Threaten to hit or injure spouse & 1.2 & 1.3 \\
\hline \multicolumn{3}{|l|}{ Physical punishment (\%within gender) } \\
\hline Spank with your hand & 32.2 & 35.5 \\
\hline Cane or hit with an object & 41.1 & 43.9 \\
\hline Shake or shove & 2.2 & 1.9 \\
\hline History of family member(s) seeing a psychiatrist (\%within gender) & 8.0 & 12.9 \\
\hline
\end{tabular}

them were Chinese, followed by Indian (7\%), Malay (4\%) and others (8\%). Seventy-seven percent of them were staying at public housing estates. The ethnic ratio and the housing distribution of the sample were comparable to those of the general population [33]. This showed that our sample was largely representative of service users of child mental health services in Singapore. There were no statistically significant differences between genders in terms of their demographics, socioeconomic variables, psychological aggression between parents and parental use of physical punishment.

CBCL internalizing problems, externalizing problems, syndrome scales and total problems were compared between genders using Mann-Whitney test (Table 2). As hypothesized, females with ADHD displayed less delinquent behavior $(U=14,042, z=-2.79, p=0.005$, $r=-0.12)$, less aggressive behavior $(U=14,905$, $z=-2.10, p=0.035, r=-0.09)$ but they were more withdrawn/depressed $(U=14,578, z=-2.38, p=0.017$, $r=-0.10$ ). Males with ADHD had a significantly higher score for externalizing problems $(U=14,747, z=-2.23$, $p=0.026, r=-0.09)$ but the gender difference in internalizing scores was not statistically significant, $U=15,659, z=-1.52, p=0.129, r=-0.06$. There was no statistically significant gender difference in attention problems.

Gender comparisons based on TRF showed similar results as CBCL (Table 2). Males with ADHD had more aggressive $(U=11,063, z=-3.40, p=0.001, r=-0.15)$ and delinquent behavior $(U=11,696, z=-2.89$, $p=0.004, r=-0.13)$. Males also had higher externalizing problem scores while females had higher internalizing scores but both differences did not reach statistical significance. In addition, males were noted to have more thought problems $(U=12,641, \quad z=-2.12, \quad p=0.034$, $r=-0.09)$, social problems $(U=12,482, \quad z=-2.18$, $p=0.030, r=-0.09$ ) and attention problems, $U=10,905$, $z=-3.53, p<0.001, r=-0.15$. Due to heterogeneity of the 12 items in thought problems, individual item was compared between genders using chi-squared tests with 
Table 2 CBCL and TRF syndrome scales, internalizing and externalizing problems by gender

\begin{tabular}{|c|c|c|c|c|c|c|c|c|}
\hline & \multicolumn{4}{|l|}{$\mathrm{CBCL}$} & \multicolumn{4}{|l|}{ TRF } \\
\hline & $\begin{array}{l}\text { Female }(n=72) \\
\text { Median } \\
(25 \text { th-75th } \\
\text { percentile) }\end{array}$ & $\begin{array}{l}\text { Male }(n=489) \\
\text { Median } \\
(25 t h-75 t h \\
\text { percentile })\end{array}$ & $P$ & $\begin{array}{l}\text { Effect size } \\
r\end{array}$ & $\begin{array}{l}\text { Female }(n=64) \\
\text { Median } \\
(25 \text { th-75th } \\
\text { percentile) }\end{array}$ & $\begin{array}{l}\text { Male }(n=468) \\
\text { Median } \\
(25 t h-75 t h \\
\text { percentile) }\end{array}$ & $P$ & $\begin{array}{l}\text { Effect size } \\
r\end{array}$ \\
\hline \multicolumn{9}{|l|}{ Syndrome scales } \\
\hline Withdrawn/depressed & $4.0(1.0-6.0)$ & $2.0(1.0-5.0)$ & 0.017 & -0.10 & $1.5(0.0-4.8)$ & $2.0(0.0-4.0)$ & 0.819 & -0.01 \\
\hline Somatic complaints & $2.0(1.0-3.75)$ & $2.0(0.0-4.0)$ & 0.416 & -0.03 & $0.0(0.0-1.0)$ & $0.0(0.0-1.0)$ & 0.930 & -0.00 \\
\hline Anxious/depressed & $5.0(2.0-9.8)$ & $5.0(2.0-8.0)$ & 0.266 & -0.05 & $2.0(0.0-5.0)$ & $1.0(0.0-4.0)$ & 0.284 & -0.05 \\
\hline Social problems & $5.5(3.3-8.0)$ & $5.0(3.0-7.0)$ & 0.159 & -0.06 & $2.0(0.0-6.0)$ & $3.5(1.0-6.0)$ & 0.030 & -0.09 \\
\hline Thought problems & $2.0(1.0-4.0)$ & $2.0(1.0-4.0)$ & 0.669 & -0.02 & $0.0(0.0-2.0)$ & $1.0(0.0-2.0)$ & 0.034 & -0.09 \\
\hline Attention problems & $10.0(7.0-12.0)$ & $10.0(7.0-12.0)$ & 0.913 & -0.00 & $15.5(8.3-22.0)$ & $20.0(13.0-26.0)$ & 0.000 & -0.15 \\
\hline Delinquent behavior & $2.0(1.0-5.0)$ & $4.0(2.0-6.0)$ & 0.005 & -0.12 & $1.0(0.0-3.0)$ & $2.0(1.0-4.0)$ & 0.004 & -0.13 \\
\hline Aggressive behavior & $12.0(8.0-17.8)$ & $14.0(8.0-21.0)$ & 0.035 & -0.09 & $4.5(1.0-17.0)$ & $11.0(3.0-22.0)$ & 0.001 & -0.15 \\
\hline Internalizing problems & $12.0(4.3-18.0)$ & $9.0(5.0-15.0)$ & 0.129 & -0.06 & $5.0(1.0-11.8)$ & $4.0(1.0-10.0)$ & 0.569 & -0.02 \\
\hline Externalizing problems & $15.5(9.3-23.0)$ & $18.0(11.0-26.0)$ & 0.026 & -0.09 & $5.5(1.0-19.8)$ & $14.5(4.0-27.0)$ & 0.335 & -0.04 \\
\hline Total problems & $50.5(34.5-67.8)$ & $50.0(34.0-69.0)$ & 0.836 & -0.01 & $32.5(15.8-53.0)$ & $48.0(28.0-67.0)$ & 0.829 & -0.01 \\
\hline
\end{tabular}

Bonferroni correction for multiple comparisons. No significant gender difference was noted in any item.

The effects of age on CBCL syndrome scales, internalizing and externalizing problems were summarized in Table 3. Compared to the younger group, the older group was found to have more internalizing $(U=7190$, $z=-2.63, p=0.009, r=-0.11)$ and externalizing problems, $U=7647, z=-2.15, \quad p=0.032, \quad r=-0.09$. The older group had significantly higher scores in withdrawn/depressed problems $(U=7532, \quad z=-2.29$, $p=0.022, \quad r=-0.10), \quad$ anxious/depressed problems $(U=7160, z=-2.67, p=0.008, r=-0.11)$, attention problems $(U=7185, \quad z=-2.64, \quad p=0.008, \quad r=-0.11)$ and delinquent behavior, $U=6804, z=-3.05, p=0.002$, $r=-0.13$.

In the multiple linear regression model predicting internalizing problem scores, the list of predictors were able to explain $9 \%$ of the variance, $F(9466)=5.29$, $p<0.001$. Among the predictors, age $(\beta=0.14, p=0.019)$, financial problems $(\beta=0.09, p=0.048)$ and physical punishment $(\beta=0.12, p=0.007)$ were significant predictors (Table 4). In the regression model predicting CBCL externalizing problem score, the list of predictors explained $11 \%$ of the variance, $F(9468)=6.26, p<0.001$. Gender $(\beta=0.17, \quad p=0.043)$, father's education level $(\beta=-0.17, p=0.002)$, psychological aggression between

Table 3 CBCL scores by age group

\begin{tabular}{|c|c|c|c|c|}
\hline & $\begin{array}{l}6-12 \text { years old }(n=524) \\
\text { Median ( } 25 \text { th-75th quartile) }\end{array}$ & $\begin{array}{l}\text { 13-18 years old ( } n=37) \\
\text { Median ( } 25 \text { th-75th quartile) }\end{array}$ & $P$ & $\begin{array}{l}\text { Effect size } \\
r\end{array}$ \\
\hline \multicolumn{5}{|l|}{ Syndrome scales } \\
\hline Withdrawn/depressed & $2.0(1.0-5.0)$ & $4.0(2.0-6.0)$ & 0.022 & -0.10 \\
\hline Somatic complaints & $2.0(0.0-4.0)$ & $2.0(1.0-4.0)$ & 0.319 & -0.04 \\
\hline Anxious/depressed & $4.0(2.0-8.0)$ & $7.0(4.5-9.0)$ & 0.008 & -0.11 \\
\hline Social problems & $5.0(3.0-7.0)$ & $6.0(2.0-9.0)$ & 0.195 & -0.05 \\
\hline Thought problems & $2.0(1.0-4.0)$ & $3.0(2.0-50)$ & 0.051 & -0.08 \\
\hline Attention problems & $10.0(7.0-12.0)$ & $12.0(8.5-13.0)$ & 0.008 & -0.11 \\
\hline Delinquent behavior & $3.5(2.0-5.0)$ & $6.0(3.0-9.0)$ & 0.002 & -0.13 \\
\hline Aggressive behavior & $14.0(8.0-20.0)$ & $17.0(9.0-23.5)$ & 0.155 & -0.06 \\
\hline Internalizing problems & $9.0(4.25-15.0)$ & $12.0(8.0-19.0)$ & 0.009 & -0.11 \\
\hline Externalizing problems & $17.0(11.0-25.0)$ & $22.0(11.0-33.0)$ & 0.032 & -0.09 \\
\hline Total problems & $49.0(34.0-67.0)$ & $63.0(40.0-76.5)$ & 0.026 & -0.09 \\
\hline
\end{tabular}


Table 4 Summary of multiple linear regressions for variables predicting CBCL internalizing and externalizing scores

\begin{tabular}{|c|c|c|c|c|c|c|}
\hline \multirow[t]{2}{*}{ Variables } & \multicolumn{3}{|c|}{$\mathrm{CBCL}$ internalizing score } & \multicolumn{3}{|c|}{ CBCL externalizing score } \\
\hline & $B$ & $S E$ & $\beta$ & $B$ & $S E$ & $\beta$ \\
\hline Gender $^{a}$ & -1.38 & 2.01 & -0.06 & 5.53 & 2.72 & $0.17^{*}$ \\
\hline Age & 0.49 & 0.21 & $0.14^{*}$ & 0.20 & 0.28 & 0.04 \\
\hline Gender $\times$ age interaction & -0.52 & 1.85 & -0.03 & -3.09 & 2.52 & -0.12 \\
\hline Mother's education ${ }^{\mathrm{b}}$ & -1.22 & 0.79 & -0.08 & -0.11 & 1.08 & -0.01 \\
\hline Father's education ${ }^{\mathrm{b}}$ & -1.04 & 0.79 & -0.07 & -3.43 & 1.08 & $-0.17^{* *}$ \\
\hline Financial problems ${ }^{c}$ & 2.46 & 1.24 & $0.09^{*}$ & -0.01 & 1.68 & 0.00 \\
\hline Psychological aggression between spouses ${ }^{d}$ & 0.59 & 0.37 & 0.07 & 1.41 & 0.51 & $0.13^{* *}$ \\
\hline Physical punishment $\mathrm{e}^{\mathrm{e}}$ & 1.21 & 0.45 & $0.12^{* *}$ & 2.38 & 0.61 & $0.18^{* *}$ \\
\hline Family member(s) seen a psychiatrist before ${ }^{f}$ & -1.87 & 1.01 & -0.08 & -2.12 & 1.37 & -0.07 \\
\hline$R^{2}$ & & 0.09 & & & 0.11 & \\
\hline F & & $5.29^{* *}$ & & & $6.26^{* *}$ & \\
\hline
\end{tabular}

$B=$ unstandardized beta coefficient, $S E=$ standard error, $\beta=$ standardised beta coefficient

${ }^{*} p<0.05$

** $p<0.01$

a Coded as $0=$ female, $1=$ male

b Coded as $0=$ secondary education or below, $1=$ post-secondary education or above

c Coded as $0=$ no financial problems, $1=$ experienced financial problems before

${ }^{d}$ Coded as $0=$ no psychological aggression between spouse, 1 to $5=1$ point for the presence of each of the following, yelling, insulting, crying, threatening to injure spouse and refusing to talk

e Coded as $0=$ no physical punishment in disciplining, $1=$ spank or hit with an object, $2=$ spank and hit with an object

${ }^{f}$ Coded as $0=$ no one in the family has ever seen a psychiatrist, $1=$ at least one family member has seen a psychiatrist

parents $(\beta=0.13, p=0.006)$ and physical punishment $(\beta=0.18, p<0.001)$ were significant predictors (Table 4$)$. No significant age $\times$ gender interaction was noted in either regression models.

\section{Discussion}

This study aimed to elucidate the gender differences in internalizing and externalizing problems in children and adolescents aged six to eighteen with ADHD using parent and teacher reports extracted from a clinical database. Consistent with studies in the West, females with ADHD presented with fewer externalizing problems than their male counterparts. In addition, females presented with more internalizing problems although it was not statistically significant.

\section{Gender difference in externalizing problems}

Gender remained a significant predictor of externalizing problem after controlling for other factors. In contrast to previous clinical studies in Asia where no gender difference was found in externalizing problems, the gender difference noted in our study could be due to two reasons. Firstly, our sample had more females which have increased the statistical power. Secondly, Singaporean parents, similar to most Asian parents, are highly concerned with academic success [34].
Singaporean parents may have a lower threshold to bring their daughters to the clinic when they are facing only academic difficulties or attention deficits, without displaying any behavioral issues.

\section{Gender difference in internalizing problems}

Females with ADHD were reported to have more internalizing problems but the difference did not reach statistical significance. This could be explained by several reasons. Firstly, only parent-reports and teacher-reports were used in assessing the internalizing problems. It has been shown that parent-reports were less sensitive and they tended to underestimate internalizing problems compared to self-reports [35, 36]. Secondly, combining different internalizing syndrome scales into one score may have masked the gender differences in individual syndrome scale. Females were found to be significantly more withdrawn and depressed while no significant gender differences were noted in somatic complaints or anxiety. In a study using self-report questionnaire, males with ADHD reported to experience higher level of anxiety than their female counterparts [37]. The opposite directions of gender differences in individual components of internalizing problems may have resulted in the lack of gender difference in the overall internalizing score. 


\section{Relationship between other factors and internalizing and externalizing problems}

In the multiple linear regressions, the regression models could only explain a small percentage of the variance in internalizing and externalizing problems respectively, suggesting that some important predictors were not included in the regression models. After controlling for potential confounders, there was no evidence of a statistically significant association between gender and internalizing problems and only a weak and marginally significant association between gender and externalizing problems. Therefore, the gender differences observed in the univariate analysis could be contributed by gender differences in the relationship between these confounding factors and internalizing or externalizing problems. However, the gender effects of these confounding factors in the ADHD population are unclear. Their potential effects were discussed below.

\section{Effect of age}

Adolescents were found to have more internalizing and externalizing problems than children. After controlling for other variables including gender, age remained a significant predictor of internalizing problems with older age having more internalizing problems. This could be due to the increase in academic demands and higher social expectation of impulse control with increasing age. Inattention, hyperactivity and impulsivity problems may become more impairing in secondary schools, leading to the development of more internalizing problems. Previous literature has shown that an earlier age of onset is associated with more externalizing problems and less internalizing problems [26]. In this study, the age of being diagnosed with ADHD was used as the age of onset was not available. Since most symptoms of ADHD would manifest in early childhood, it is possible that those diagnosed at adolescence may have a longer duration of untreated ADHD leading to a greater severity of impairment. To test this hypothesis, accurate age of onset is needed. However, recall bias is a common obstacle in retrospective research, especially in ADHD studies where symptoms can manifest at a very young age.

\section{Effect of socioeconomic status}

In this study, children and adolescents with ADHD of lower socioeconomic status had more internalizing and externalizing problems. Among studies on socioeconomic status and ADHD prevalence, it remained inconclusive whether low socioeconomic status could be a risk factor for ADHD [6]. Our results suggest a need for intervention targeting internalizing and externalizing problems in ADHD children from families of low socioeconomic status. Raising public awareness of ADHD may facilitate early help seeking from parents of lower education levels.

\section{Effect of physical punishment and spouse aggression}

Consistent with the literature, physical punishment such as caning and spanking was associated with more internalizing and externalizing problems [38]. Based on social learning theory [39], physical punishment can model aggressive behavior of a child and the theory has been confirmed repeatedly in empirical research [38]. Males were found to be more likely than females to receive physical punishment from parents and the effect of physical punishment also differed between genders [40]. Furthermore, self-control was reported to be lower in males disciplined with spanking but no significant difference was noted in females disciplined with spanking [41]. All these evidences suggest that males with ADHD are more likely to receive physical punishment and subsequently perceive poorer self-control and display more aggressive behaviors than females with ADHD. Similar to physical punishment, psychological aggression between parents could have modelled aggressive behaviors in children. While most studies on the effect of physical punishment were done in general population, this study only included participants with ADHD. Future studies should explore whether ADHD could be a moderator on the effect of physical punishment on internalizing and externalizing problems. A recent local study has reported that use of physical punishment was more common in mothers of ADHD children compared to typically developing children but the causal relationship between the use of physical punishment and the children behavioral problems remains unclear [42]. As physical punishment is more widely accepted in the Asian culture, its effect on children development may be different from the West.

\section{Gender differences in thought problems}

Although males with ADHD had more thought problems than females with ADHD according to teacher-reports, no statistically significant gender difference was noted on individual items. Since these items described symptoms from a range of heterogeneous disorders including psychotic disorders and obsessive-compulsive disorder, more comprehensive assessment of these disorders is needed before we can establish their severity and prevalence for gender comparison. Furthermore, the low prevalence of thought problems in children and adolescents necessitates a larger sample for comorbidity study. The gender differences in thought problems observed by teachers in this study may reflect problems in inattention, impulsivity or hyperactivity e.g. "can't keep his/her mind off certain thoughts", "twitching", "deliberately harm self", "pick nose" and "strange behaviors". 


\section{Gender differences in social problems}

Teachers reported more social problems in males than females with ADHD in the current study. It has been known that both genders with ADHD suffer from social problems including peer rejection and victimization [4346]. However, little is known about the gender differences in this problem. Males with ADHD may present with more covert aggression and disruptive behavior, resulting in more obvious peer rejection in school. As females and males have different social interaction style, their degree and nature of social dysfunction could be different [47, 48].

\section{Implications and further studies}

Unlike most clinical studies, participants in this study were all newly diagnosed with ADHD and were treatment naïve. Hence, the results were not confounded by interventions. The study has also included the largest number of females with ADHD among studies on gender differences in ADHD in Asia to date. With more female subjects, we were able to capture the gender differences that were not reported previously among young persons with ADHD in Asia. The findings suggest that in the clinical population, males and females with ADHD could present with different comorbidity profiles. Awareness of the gender-specific comorbidity profiles and management addressing the specific needs is warranted.

Although gender differences in ADHD symptoms and comorbidity have been reported more than two decades ago, the causes were not clearly understood. Structural and functional neuroimaging studies have shown numerous gender differences in neuroanatomy and neural network activities [49]. For example, it has been suggested that overproduction of striatal dopamine receptors could be the cause of hyperactivity in male early developmental period [50]. At the molecular level, gender differences in genetics and sex hormones could modulate neuronal development and led to gender differences in neurodevelopmental disorders such as ADHD [51]. However, more research is needed to understand the biological basis of gender differences in ADHD symptoms. Other than biological mechanism, social factors such as socioeconomic status, use of physical punishment and psychological aggression between parents could have an effect on the gender differences in ADHD as suggested in our study. Each of these variables necessitates further research with more well established instruments in order to understand their effect on gender differences.

The lack of externalizing symptoms in females with ADHD may have delayed referral to the professional. A study on barriers to treatment in ADHD has suggested that parents of daughters with high risks of ADHD were less likely to seek help than parents of males with similar problems [52]. Parental perception of ADHD treatment played an important role too as Bussing et al. [52] have suggested a higher perceived stigma for ADHD treatment of daughters than of sons. More research on parental understanding on ADHD, threshold to treatment and stigma is needed in order to improve help seeking in females with ADHD. Furthermore, whether the behavior is labelled as problematic or not could be cultural dependent. Multiethnic study is needed to explore the different cultural thresholds and Singapore, with its multiethnic population, could be a potential study site.

During assessment, clinician should be mindful of the gender differences in the symptoms presented. Gender specific threshold in symptom lists or diagnostic instrument could be a possible solution. However, there is a risk of overdiagnosis in females and it was suggested that the impairment criterion should remain the same for both genders [7]. At the moment, clinicians are still recommended to follow the same diagnostic criteria for both genders. Moreover, further research is needed to explore gender differences in neuropsychological tests in both the ADHD and general population in order to understand whether a gender specific cut off score is necessary. To prevent misdiagnosis, clinician should also consider $\mathrm{ADHD}$ as a possible differential diagnosis apart from a mood disorder when they assess females with depressed mood and social withdrawal.

As most studies in female ADHD were based on clinical samples, characteristics of those that were not referred remained largely unknown. Future study using a community sample would help us understand the characteristics of this non-referred ADHD population. A community study would also promote understanding on the inherent gender difference on attention, hyperactivity and impulsivity in the general population. This information would be crucial in development of any gender-specific diagnostic tool or criteria. Apart from clinical criteria, future studies should explore gender differences in commonly used neuropsychological assessment in the ADHD population. This would allow more accurate interpretation of assessment.

\section{Limitations}

There were several limitations in this study. Firstly, the participants were not recruited by nationwide population sampling although they were recruited from the largest child and adolescent psychiatric center in Singapore. Secondly, database was incomplete due to missing data. Thirdly, the database was collected more than ten years ago but it was the largest and most comprehensive of the ADHD clinical population available at the time of the study. Since gender differences in ADHD in externalizing and internalizing problems have been consistently 
reported over the years, we expect minimal effect of the time gap on the generalizability of our results.

\section{Conclusion}

This study shows that gender differences in comorbidity profiles do exist in Asian ADHD population with males having more externalizing problems than females. Although females were shown to have more internalizing problems than males in the literature, the difference was not significant in our sample. In addition, experiences of physical punishment and lower socioeconomic status were associated with more internalizing and externalizing problems. With other covariates being controlled, age was a better predictor of internalizing problems than gender while gender was a better predictor for externalizing problems than age.

Our results showed that a multi-pronged approach is needed to improve detection of females with ADHD who usually present with fewer externalizing problems. At the parent and school level, we need to improve parental and teachers' awareness of ADHD and promote help seeking behavior. At the clinician level, we need to re-examine whether gender-specific criteria are needed for diagnosis and whether certain neuropsychological assessments should have gender specific cut off scores.

\begin{abstract}
Abbreviations
ADHD: Attention-deficit/hyperactivity disorder; ANOVA: Analysis of variance; CBCL: Child Behavior Checklist; DDP: Department of Developmental Psychiatry; ICD-9-CM: International Classification of Diseases, Ninth Revision, Clinical Modification; IMH: The Institute of Mental Health; TRF: Teacher's Report Form.
\end{abstract}

\section{Acknowledgements}

Not applicable.

\section{Authors' contributions}

TWIL designed the study with support from CGL and SSDF, obtained data with support from YRT, analyzed and interpreted data with support from SA and NL and drafted the manuscript. All authors read and approved the final manuscript.

\section{Funding}

No funding was involved in the current study.

\section{Availability of data and materials}

The datasets used and/or analyzed during the current study are available from the corresponding author on reasonable request.

\section{Ethics approval and consent to participate}

All data was collected as part of routine assessments at the first clinic consultation. Written consents to use the collected data for research purposes were obtained from parents. The study has been approved by the Institutional Research Review Committee at the Institute of Mental Health and the National Healthcare Group Domain Specific Review Board.

\section{Consent for publication}

Not applicable.

\section{Competing interests}

The authors declare that they have no competing interests.

\section{Author details}

${ }^{1}$ The Institute of Mental Health, Buangkok Green Medical Park 10 Buangkok View, Singapore 539747, Singapore. ${ }^{2}$ Duke-NUS Medical School, 8 College Road, Singapore 169857, Singapore.

Received: 20 July 2020 Accepted: 11 January 2021

Published online: 22 January 2021

\section{References}

1. Singapore Department of Statistics. Population and population structure. 2019. https://www.singstat.gov.sg/find-data/search-by-theme/popul ation/population-and-population-structure/latest-data. Accessed 1 Dec 2019.

2. American Psychiatric Association. Diagnostic and statistical manual of mental disorders: DSM-IV-TR. 4th ed. Washington, DC: American Psychiatric Association; 2000.

3. Polanczyk G, de Lima MS, Horta BL, Biederman J, Rohde LA. The worldwide prevalence of ADHD: a systematic review and metaregression analysis. Am J Psychiatry. 2007;164:942-8.

4. Woo BS, Ng TP, Fung DS, Chan YH, Lee YP, Koh JB, et al. Emotional and behavioural problems in Singaporean children based on parent, teacher and child reports. Singap Med J. 2007:48:1100-6.

5. Lim CG, Ong SH, Chin CH, Fung DSS. Child and adolescent psychiatry services in Singapore. Child Adolesc Psychiatry Ment Health. 2015;9:1-7.

6. Willcutt EG. The prevalence of DSM-IV attention-deficit/hyperactivity disorder: a meta-analytic review. Neurotherapeutics. 2012;9:490-9.

7. Arnold LE. Sex differences in ADHD: conference summary. J Abnorm Child Psychol. 1996;24:555-69.

8. Byun H, Yang J, Lee M, Jang W, Yang J, Kim J, et al. Psychiatric comorbidity in Korean children and adolescents with attention-deficit hyperactivity disorder: psychopathology according to subtype. Yonsei Med J. 2006;47:113-21.

9. Gaub M, Carlson CL. Gender differences in ADHD: a meta-analysis and critical review. J Am Acad Child Adolesc Psychiatry. 1997;36:1036-45.

10. NøvikTS, Hervase A, Ralston SJ, Dalsgaard S, Pereira RR, Lorenzo MJ. Influence of gender on attention-deficit/hyperactivity disorder in EuropeADORE. Eur Child Adolesc Psychiatry. 2006;15:15-24.

11. Yang P, Jong YJ, Chung LC, Chen CS. Gender differences in a clinicreferred sample of Taiwanese attention-deficit/hyperactivity disorder children. Psychiatry Clin Neurosci. 2004;58:619-23.

12. Biederman J, Mick E, Faraone SV, Braaten E, Doyle A, Spencer T, et al. Influence of gender on attention deficit hyperactivity disorder in children referred to a psychiatric clinic. Am J Psychiatry. 2002;159:36-42.

13. American Psychiatric Association. Diagnostic and statistical manual of mental disorders. 5th ed. Washington, DC: American Psychiatric Association; 2013.

14. Arnett AB, Pennington BF, Willcutt EG, DeFries JC, Olson RK. Sex differences in ADHD symptom severity. J Child Psychol Psychiatry. 2015:56:632-9.

15. Gershon J. A meta-analytic review of gender differences in ADHD. J Atten Disord. 2002:5:143-54.

16. Waschbusch DA, King S. Should sex-specific norms be used to assess attention-deficit/hyperactivity disorder or oppositional defiant disorder? J Consult Clin Psychol. 2006;74:179-85.

17. Ramzi H, Fine JG. Gender differences among children with ADHD on continuous performance tests: a meta-analytic review. J Atten Disord. 2012;16:190-8.

18. Abikoff HB, Jensen PS, Arnold LLE, Hoza B, Hechtman L, Pollack S, et al. Observed classroom behavior of children with ADHD: relationship to gender and comorbidity. J Abnorm Child Psychol. 2002;30:349-59.

19. Ghanizadeh A, Mohammadi MR, Moini R. Comorbidity of psychiatric disorders and parental psychiatric disorders in a sample of Iranian children with ADHD. J Atten Disord. 2008;12:149-55.

20. Levy F, Hay DA, Bennett KS, McStephen M. Gender differences in ADHD subtype comorbidity. J Am Acad Child Adolesc Psychiatry. 2005:44:368-76.

21. Solberg BS, Halmøy A, Engeland A, Igland J, Haavik J, Klungsøyr K. Gender differences in psychiatric comorbidity: a population-based study of 
40000 adults with attention deficit hyperactivity disorder. Acta Psychiatr Scand. 2018;137:176-86.

22. Rucklidge JJ, Tannock R. Psychiatric, psychosocial, and cognitive functioning of female adolescents with ADHD. J Am Acad Child Adolesc Psychiatry. 2001;40:530-40.

23. Dalsgaard S, Mortensen PB, Frydenberg M, Thomsen PH. Conduct problems, gender and adult psychiatric outcome of children with attentiondeficit hyperactivity disorder. Br J Psychiatry. 2002;181:416-21.

24. Biederman J, Mick E, Faraone SV. Age-dependent decline of symptoms of attention deficit hyperactivity disorder: impact of remission definition and symptom type. Am J Psychiatry. 2000;157:816-8.

25. Hurtig T, Ebeling H, Taanila A, Miettunen J, Smalley SL, McGough JJ, et al. ADHD symptoms and subtypes: relationship between childhood and adolescent symptoms. J Am Acad Child Adolesc Psychiatry. 2007:46:1605-13.

26. Connor DF, Edwards G, Fletcher KE, Baird J, Barkley RA, Steingard RJ. Correlates of comorbid psychopathology in children with ADHD. J Am Acad Child Adolesc Psychiatry. 2003;42:193-200

27. Ang RP, Rescorla LA, Achenbach TM, Ooi YP, Fung DSS, Woo B. Examining the criterion validity of CBCL and TRF problem scales and items in a large Singapore sample. Child Psychiatry Hum Dev. 2012;43:70-86.

28. Achenbach TM, Rescorla LA. Manual for the ASEBA school-age forms \& profiles. Burlington: University of Vermont, Research Center for Children, Youth, \& Families; 2001.

29. Boyle MH, Offord DR, Hofmann HG, Catlin GP, Byles JA, Crawford JW, et al. Ontario child health study I. Methodology. Arch Gen Psychiatry. 1987:44:826-31.

30. Straus MA, Hamby S, Boney-McCoy S, Sugarman D. The revised conflict tactics scales: development and preliminary psychometric data. J Fam Issues. 1996;17:283-316.

31. Field A. Discovering statistics using SPSS. 3rd ed. London: Sage Publication Ltd; 2009

32. Lim CG, Ooi YP, Fung DS, Mahendran R, Kaur A. Sleep disturbances in Singaporean children with attention deficit hyperactivity disorder. Ann Acad Med Singap. 2008;37:655-61.

33. Housing and Development Board. Key statistics. 2013. http://www20.hdb gov.sg/fi10/fi10320p.nsf/ar2014/pdf/HDB_KeyStatistics_13_14_d9_HiRes .pdf. Accessed 12 Dec 2019.

34. Ang RP, Klassen RM, Chong WH, Huan VS, Wong IF, Yeo LS, et al. Crosscultural invariance of the academic expectations stress inventory: adolescent samples from Canada and Singapore. J Adolesc. 2009;32:1225-37.

35. Faraone SV, Biederman J, Milberger S. How reliable are maternal reports of their children's psychopathology? One-year recall of psychiatric diagnoses of ADHD children. J Am Acad Child Adolesc Psychiatry. 1995;34:1001-8

36. Skogli EW, Teicher MH, Andersen PN, Hovik KT, Øie M. ADHD in girls and boys - gender differences in co-existing symptoms and executive function measures. BMC Psychiatry. 2013;13:298.
37. Mitchison GM, Njardvik U. Prevalence and gender differences of ODD, anxiety, and depression in a sample of children with ADHD. J Atten Disord. 2019;23:1339-45.

38. Ferguson CJ. Spanking, corporal punishment and negative long-term outcomes: a meta-analytic review of longitudinal studies. Clin Psychol Rev. 2013;33:196-208.

39. Bandura A. Social learning theory. London: Prentice Hall; 1977.

40. Kochanska G, Barry RA, Stellern SA, O'Bleness JJ. Early attachment organisation moderates the parent-child mutually coercive pathway to children's antisocial conduct. Child Dev. 2009;80:1288-300.

41. Shoenberger N, Rocheleau GC. Effective parenting and self-control: difference by gender. Women Crim Justice. 2017;27:1-16.

42. Nomanbhoy A, Hawkins R. Parenting practices of Singaporean mothers of children with ADHD. Proc Singap Healthc. 2018;27:33-40.

43. Aduen PA, Day TN, Kofler MJ, Harmon SL, Wells EL, Sarver DE. Social problems in ADHD: is it a skills acquisition or performance problem? Psychopathol Behav Assess. 2018;40:440-51.

44. Carpenter RE, Loo SK, Yang M, Dang J, Smalley SL. Social functioning difficulties in ADHD: association with PDD risk. Clin Child Psychol Psychiatry. 2009;14:329-44.

45. Deboo G, Prins P. Social incompetence in children with ADHD: possible moderators and mediators in social-skills training. Clin Psychol Rev. 2007;27:78-97.

46. Hoza B. Peer functioning in children with ADHD. J Pediatr Psychol. 2007:32:655-63.

47. Kok FM, Groen Y, Fuermaier AB, Tucha O. Problematic peer functioning in girls with ADHD: a systematic literature review. PLOS ONE. 2016;11:e0165119.

48. Ragnarsdottir B, Hannesdottir DK, Halldorsson F, Njardvik U. Gender and age differences in social skills among children with ADHD: peer problems and prosocial behavior. Child Fam Behav Ther. 2018;40:263-78.

49. Nussbaum NS. ADHD and female specific concerns: a review of the literature and clinical implications. J Atten Disord. 2012;16:87-100.

50. Anderson SL, Teicher MH. Sex differences in dopamine receptors and their relevance to ADHD. Neurosci Biobehav Rev. 2000;24:137-41.

51. Varshney M, Nalvarte I. Genes, gender, environment, and novel functions of estrogen receptor beta in the susceptibility to neurodevelopmental disorders. Brain Sci. 2017:7:24.

52. Bussing R, Zima BT, Gary FA, Garvan CW. Barriers to detection, help-seeking, and service use for children with ADHD symptoms. J Behav Health Serv Res. 2003;30:176-89.

\section{Publisher's Note}

Springer Nature remains neutral with regard to jurisdictional claims in published maps and institutional affiliations.
Ready to submit your research? Choose BMC and benefit from:

- fast, convenient online submission

- thorough peer review by experienced researchers in your field

- rapid publication on acceptance

- support for research data, including large and complex data types

- gold Open Access which fosters wider collaboration and increased citations

- maximum visibility for your research: over $100 \mathrm{M}$ website views per year

At BMC, research is always in progress.

Learn more biomedcentral.com/submissions 